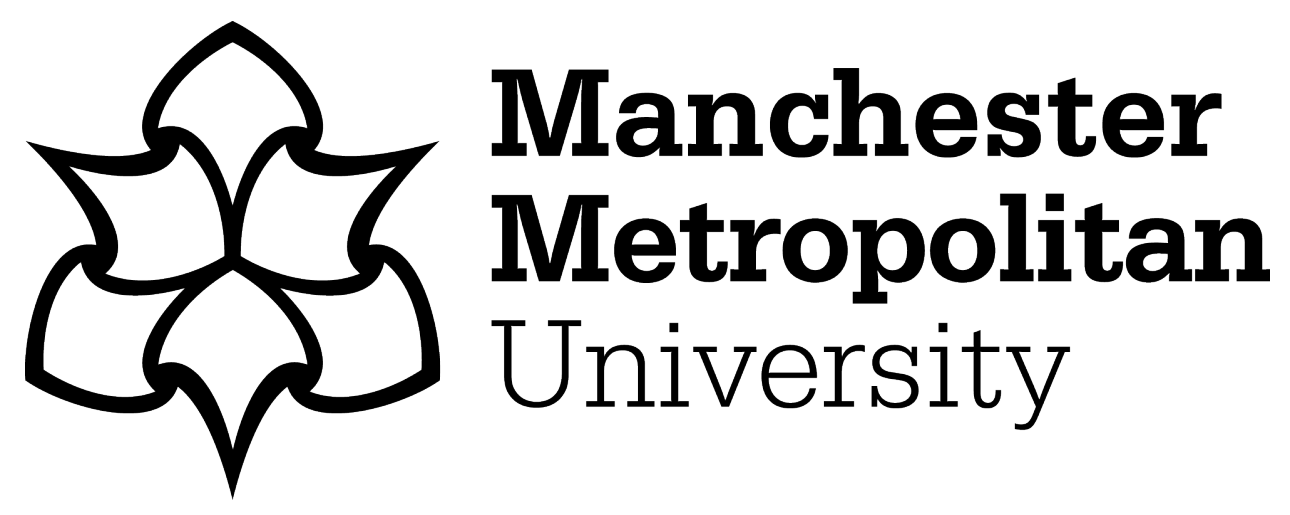

Menendez Alvarez-Hevia, D (2018) The Emotional Learning of Educators Working in Alternative Provision. Educational Studies, 54 (3). pp. 303-318. ISSN 0013-1946

Downloaded from: https://e-space.mmu.ac.uk/619190/

Version: Accepted Version

Publisher: Taylor \& Francis for American Educational Studies Association (AESA)

DOI: https://doi.org/10.1080/00131946.2017.1356307

Please cite the published version 
David Menendez Alvarez-Hevia (2017): The Emotional Learning of Educators

Working in Alternative Provision, Educational Studies

To link to this article: http://dx.doi.org/10.1080/00131946.2017.1356307

\title{
THE EMOTIONAL LEARNING OF EDUCATORS WORKING IN ALTERNATIVE PROVISION
}

\section{Dr David Menendez Alvarez-Hevia}

\begin{abstract}
Working with pupils who are on the edge of exclusion is not an easy job; in fact, it is more than just a job. This study investigates the emotional involvement of educators (teachers and mentors) working with pupils who have been permanently, or are at risk of being, excluded from mainstream education The article presents different forms of emotional learning that take place in educational practice. Specifically, it explores the emotional relationships that educators have with pupils and each other. It also draws on the concept of "emotional geography" (Hargreaves, 2001a, 2001b) to theorise the emotional interactions that the educators are expected to have with their pupils, since overcoming emotional distance is seen as a vitally important part of their work as educators of excluded pupils. The research shows that emotional learning is understood by educators as a dynamic process which they can play a part in shaping, rather than being a passive process in which they are silent actors, and that harmful experiences can have a constructive outcome.
\end{abstract}

Keywords: Emotional geography, emotional learning, alternative education, referral unit

Western societies have lived through an "emotional revolution" (Reddy, 2001) in which issues deemed "emotional" have become a "hot topic" (Evans, 2001). This article expands the conversation about the "emotional revolution" to the field of education (e.g. Pekrun \& Linnenbrink-Garcia, 2014; Schutz \& Pekrun 2007) and organisational settings (e.g. Fineman, 2000; Fisher \& Ashkanasy, 2000, 2003; Goleman, 1999). While this new interest in emotional matters has contributed to the articulation of discourses about emotions that transform the perception of personal relations in schools, and the ways in which educators display their emotional involvement and subjectification, there have been few studies on teachers' emotions and the emotional learning of educators, although (Sutton \& Wheatley, 2003; Van Veen \& Lasky, 2005; Zembylas \& Schutz, 2009) are exceptions. Understanding how emotional learning happens may stimulate fresh insight into teaching, leading to "new approaches for supporting teacher learning and for aiding school improvement efforts" (Sutton \& Wheatley, 2003, p. 351). In addition, insight into the emotional learning of teachers also works against the current dehumanisation of the teaching profession (Shapiro, 2010) by recognising ways in which educators can be supported to face the emotional demands of their job (Kerr \& Brown, 2016). As Zembylas (2007a) posits, the dehumanisation of the teaching profession is a way of exploiting and constraining the emotional capital of educators with the intention of configuring educators' emotional experiences in a normative way that contributes to the socialisation of their bodies. Paying attention to emotional aspects of teaching does not only helps to understand every day pedagogical practices but also brings new possibilities and relations without sentimentality (Zembylas, 2016, 2017).

The purpose of this article is to analyse the emotional learning of educators. In particular, it brings together Hargreaves' (2001a, 2001b) concept of “emotional geography” and Zembylas' (2014, 2005a) poststructural approach to the study of teachers' emotions. By emotional geography, I refer to a 
conceptual tool for the process by which educators learn to organise their emotional experiences and discuss points of social connection and disconnection that map different possibilities of emotional subjectivities and emotional learning. This study puts "emotional geography" to work in order to examine educators' emotional interactions with pupils in a pupil referral unit (PRU) in North-West England. PRUs are also known in the international context variously as short-stay schools, school rehabilitation facilities, pupil reintegration units or alternative education programmes. PRUs are facilities that provide education services for pupils who have been expelled or are at risk of exclusion from mainstream schools because of emotional or behavioural problems.

Specific cases of subjective emotional distances between educators and pupils, and how they connect with forms of emotional learning, are discussed. The article includes the following sections: an introduction to the theoretical framework of the study in which key concepts such as emotional exploitation, emotional learning and emotional geographies are defined; the context and methodology of the study, including an international overview of alternative provisions similar to PRUs; a discussion of three important elements of the educator-pupil relationship that allow us to understand how educators' emotionality is assembled; and a conclusion that summarises previous ideas.

\section{Conceptual frameworks of the study: Emotional exploitation, emotional learning and emotional geographies}

This article is particularly motivated by the work of three authors who generate a discussion that attempts to represent how educators might be understood in the context of living out their emotional experiences in different educational contexts. Zembylas' poststructural study of teachers' emotions and identity allowed me to understand the discursive nature of emotions (e.g. 2014, 2003, 2005b, 2007b). Hargreaves' conceptual tool of emotional geographies invited me to examine the emotional dynamics of the relationships between educators and pupils as a way of discussing forms of emotional understanding (e.g. 1998, 2001a). Finally, Boler's (1999) critical exploration of the politics of emotions provides the theoretical framework with which to approach the study of emotions as something embedded in power relations, ideology and culture. Following the idea that emotions emerge from a dynamic process of discursive practices (Zembylas, 2005a), this paper approaches emotional learning as a discursive matter materialised in different strategies and practices. In other words, emotional learning is understood as the process of interiorisation and assimilation of the different discourses about emotions that come together to articulate the emotional experience of educators.

The idea of emotional exploitation has developed from the work of Hochschild (2003) on emotional labour which helps us to understand some of the negative aspects of being emotionally exposed at work. It has been associated with the work developed by educators (Chang, 2009; Colley, 2006; Freid, 1996; Nias, 1996; Priece, 2001) and this concept can be used to understand the costs of developing a work activity that "emphasises the relational rather than the task-based aspects of work" (Steinberg \& Figart, 1999, p. 9). Emotional labour is a broad concept that can be used to describe: various aspects of interpersonal interactions in education, including face-to-face contact with different publics (e.g. pupils, parents, inspectors, etc.); continuous efforts to produce an emotional state in other people (generally in pupils); submission; open resistance or subversive transgression to a managerial system of emotional control (curriculum, educational policy, etc.); or/and the promotion of emotional states that can be "sold" (e.g. happy faces in the classroom).

The idea of emotional geography is used in this research to organise and explore educators' discourses and note tensions that help to foreground how teachers understand, learn to deal with and characterise the emotional aspects of their labour. In the words of Hargreaves (2001a), "the concept of emotional geography helps us identify the supports for and threats to the basic emotional bonds and 
understanding of schooling that arise from forms of distance or closeness in people's interaction or relationships" (p. 1057).

Emotional geography is a conceptual tool used to recognise the emotional learning of teachers by looking at emotional interactions in relation to a symbolic emotional space defined in terms of lesser or greater distance (Hargreaves, 2000, 2001a, 2001b, 2004). In line with Hargreaves (2001a, p. 1057), all forms of teaching are "inextricably emotional - by design or default" and teaching must be understood as an emotional practice (Denzin, 2007; Zembylas, 2003). This paper will bring into discussion the three aspects of Hargreaves' (2000, 2001a, 2001b, 2004) emotional geography described below:

(a) There are no natural or universal rules about emotions. Universality and the natural production and representation of emotions are challenged from socio-cultural and postmodern approaches that view emotions not only as biologically constituted, but as socio-cultural and political products existing in the form of discursive practices (Egerton, 1995; Zembylas, 2005b) or narratives (Beatty, 2014) that, for example, differ in time, idiom or expression (Harré, 1986; Harré \& Parrot, 1996). Emotional cultures differ from one school to another, but even within the same school, teachers can be subjected to the same experience in different ways. It is through "emotional rules" and "emotional discourses" that is sustained and embraced the idea that emotions can be standardised for all teachers and thus perceived as "naturally" constructed, overlooking its more subjective interpretations (Zembylas, 2005b)

(b) Emotional distance is symbolic. Rather than physical distance that can be measured as separation in metres, miles, inches or microns, in this research, I am trying to interrogate subjective emotional distances that are experienced by educators. Therefore, the emotional experience is not described as a physical phenomenon; the way that it is lived by educators is historically and politically determined and it is understood on a subjective level. Ahmed (2015) illustrates how the emotional world is ideologically, historically and culturally shaped, producing social interactions. Additionally, the three years ethnographic and genealogical study carried out by Zembylas (2002) with science teachers showed the value of developing historical analysis of emotions For this reason, that this distance should not be associated only with physical representation. Although this study is not exploring in depth specific histories of emotions, it is recognised its influence to develop a multidimensional understanding of emotional interactions

(c) Lesser and greater distance have a symbolic value and are presented here as discursive products. They are constructed and articulated by "statements that occur inside the validating, material framework of the larger patterns of discourse" (Schneck, 1987, p. 20). Emotional distance is understood in this paper as discursive, because it is through discursive practices along with socio-cultural, historical and context-specific rules disciplining emotions (Zembylas, 2005b), that the perception of emotional space is determined and categorised as appropriate or inappropriate. Therefore, distances have a symbolic meaning that is defined by discourses attached to dynamic and subjective interests rather than as something that responds to a natural order.

\section{Methodology of the study: Context, subjects and data}

Taking an interpretivist approach influenced by poststructural ideas, this study analyses educators' emotional labour with pupils who have been permanently excluded or who are at risk of exclusion from their schools. The study takes place in a PRU located in an urban area of north-west England (United Kingdom). PRUs are a form of alternative education provision created to guarantee certain pupils their right to receive education. In England, pupils who are excluded or suspended from mainstream or special schools for different reasons receive this form of education with the intention of preparing them to be reallocated to new mainstream schools (Foley \& Pang, 2006; Pomeroy, 2000). Alternative 
provisions are diverse and vary across countries in terms of their delivery model, length, purpose and organisation (Gurtheson et al., 2011; Harper et al., 2011). Countries such as Canada (activity centres), France (schools of educational reinsertion), Australia (social integration units or positive learning centres) and Poland (youth socio-therapy centres) follow a similar model. However, there are other countries (e.g. Sweden, Spain, Portugal and Greece) that do not have specific alternative provisions beyond mainstream education for pupils who have challenging behaviour or emotional problems or who are at risk of disengagement. Farouk (2014) suggests that the proliferation of alternative school provision responds to the establishment of neoliberal agendas in which challenging pupils pose a problem that needs to be addressed.

The unit in question is populated by 13 pupils of between 5 and 11 years old who have been excluded from previous schools for their extreme behaviour. Two types of educators work in this unit: two qualified teachers who focus on supporting pupils with their academic development; and five mentors who support the socio-emotional development of the pupils. The role of the mentor is to support teachers' activities within the classroom but also to organise other activities that take place outside of the unit (e.g. day trips, visits to museums, etc.). The mentors act as a bridge between pupils and their families and operate on a more personal level that brings them into contact with the pupils' sociocultural and emotional contexts. Previous literature defines the experience of those working on PRUs as stimulating, intense and personally engaging, an experience, in fact, that has the potential to transform their worldview (Farouk, 2014). The working experience of these educators is mainly characterised by the fact that they are dealing with "young people who were at the very margins of the system" (Pirrie et al., 2011, p. 536). Therefore, for the purposes of this paper, the emotionality experienced by the educators working in this context cannot be assumed to be the same as that of educators in a mainstream school. Nor can we assume that emotionality within any one setting is experienced as a collective, homogeneous event.

This paper presents the experience of a PRU that illustrates the relationships and interactions of their educators and pupils. A series of 14 semi-structured interviews of 30-45 minutes each in the form of focus groups, together with three months observing the daily life of the unit are drawn on as a way of interpreting the lived interactions within it. The group Interviews with mentors and teachers were conducted at the end of the day, starting with a simple question about their day and how they feel about it. The issues that emerged from this initial question were discussed in group and to facilitate the discussion of more specific matters, the researcher also introduced ideas developed from observations.

The combination of interviews and observations is used to make tangible the interlink between educational practices and the emotional phenomenon (Watkins, 2016). The focus group is seen as "a collectivistic rather than an individualistic research method that focuses on the multivocality of participants' attitudes, experiences and beliefs" (Madriz, 2000, p. 836). Through this method, the research obtains a collective testimony by means of a less intimidating type of interview, bearing in mind that talking about emotions could be a sensitive topic (Lee \& Renzetti, 1993). Focus groups facilitate the disclosing of insider conversations through group support and reassurance (Kitzinger \& Farquhar, 1999; Liamputtong 2007, 2016). Because a sensitive topic was being researched, this method of generating data was chosen instead of individual interviews. The focus group interviews were used as an opportunity to observe how different emotional discourses intertwine and interact and how episodes considered emotionally significant are interpreted differently by the various participants.

The representation of the emotional learning of educators will be presented in this paper only with regard to their relations with pupils. The data from interviews and observations is associated with literature on teachers' emotions and used to create a narrative that does not claim to capture the full experience, but to provide some insight into the emotional interactions and learning of educators. The transcription and analysis of interviews is approached as an opportunity to explore different meanings of the educators' experiences. However, data obtained from interviews and observations are approached 
cautiously, not as a single or direct representation of the educators' reality, but as an opportunity to interweave them with other texts that open up the discussion of educators' emotionality. The researcher plays an active role facilitating discussion and generating data, but also is responsible of the data analysis that instantiate the process of meaning making. Therefore, the analysis presented in the next section is a rhetorical product that rather than claiming an accurate-real account represents the researcher construction. The value of the ideas presented in this paper does not rely on a single truth or 'real' representation, but on its capacity to develop arguments that readers might use to articulate their own ideas.

\section{The educator-pupil emotionality in a PRU}

The article now turns to exposing and discussing the emotional geography of educators and pupils, drawing on the idea that this emotional geography is central to a discussion of issues surrounding emotional learning. In the first section, the emotional involvement of an educator is presented as a dynamic phenomenon based on moments of connection and disconnection. It is then argued that educators' emotionality is in constant negotiation and connected to personal stories. Finally, the way in which the experience of working in a PRU encourages educators to redefine their perception of the pupils and the education system is discussed.

\section{Understanding emotional involvement as a pendulum-like motion}

This narrative evidences how educators and pupils develop an emotional relationship that is presented here through a metaphor of movement. The reason for using linguistic formulations associated to movement responds to the etymological origin of the word emotion and its historical understanding as a dynamic process. This idea is rooted in the way that western cultures approach emotional matters (Oatley, 2004).

Marcus is a volunteer who worked face to face with the pupils, both in the unit supporting them during teaching sessions, but also outside of it, taking pupils to participate in other activities such as visits to museums, sport events and social gatherings. Over a series of months working with Paul, a pupil labelled by social workers and educational psychologists as having severe emotional and behavioural difficulties, Marcus started to recognise changes in his relationship with Paul. At the beginning, he felt that the pupil was distant and it was not easy to understand what was going on in his head. However, after various attempts to gain Paul's trust by talking to him and finding out more about his personal interests and emotional experiences, Marcus managed to establish what he considered a good relationship with him and Paul's resistance to the two of them working together started to lessen. Paul became more open to discussing personal issues with Marcus and participated more in group activities. Marcus explained that taking Paul's emotional circumstances into consideration had a positive impact on their relationship. This relationship was based on his efforts to establish what Denzin (2007) describes as emotional understanding.. From this perspective, Marcus was trying to engage in a deeper communication process with Paul by making an effort to get closer to him with the intention of trying to understand his emotional experiences.

The educator-pupil relationship develops a pendulum-like motion. When the emotional geography was close by, Marcus explained that he was able to uncover and understand different aspects of the difficult personal circumstances that Paul was experiencing. He even found that Paul wanted to speak to him about his personal circumstances and considered himself to be in a position of trust and privilege that the pupil valued his opinion. Marcus was enjoying his work with Paul, and from his privileged position in closer proximity to him he could mediate some of Paul's problems that social workers and educational psychologists had no idea of because they were more distant from him. The 
short period of time in which things were going well with Paul was what one of Marcus' colleagues called the honeymoon period. This period is characterised by positive changes in the behaviour and attitude of pupils as described by an educator from the PRU during a conversation about the progress of one of the pupils:

Something has changed, the way he speaks, the way he says your name. It is totally different to the way he used to say, now he is warmer, wonderful, it is a change (Focus group 5).

However, changes are not permanent and educators are aware of this fragility. The staff working in this PRU are used to seeing how what they perceive as constructive moments with the pupils can turn so easily into situations that become shocking and damaging instead. This is an important point, because all these continuous changes modify the way that educators feel and their expectations with regard to the pupils:

We had wonderful moments, I do remember times with Paul so much, now I struggle very much with him because he shouldn't be here, it is damaging for him, damaging for the other kids and damaging for me! (Focus group 5).

Marcus also experienced this transformation during his work with Paul. Unexpectedly, one day, he realised that the close relationship he had built with this particular pupil was ruined and that Paul had gone back to his original behaviour; he was evasive and did not want to talk any more about personal issues. Marcus was worried and hurt and Paul's behaviour began to seriously affect him. He described an experience with Paul on a trip to a museum as humiliating and shocking. During this excursion, the pupil was swearing continuously in front of other people, making Marcus feel embarrassed about what the other teachers would think of the way he was trying to control the situation. He was trying to repair the relationship he had with Paul so he was keeping as calm as possible as a means by which to hopefully achieve rapprochement. The worst moment was when Paul ran away and Marcus had to search for him around the museum, asking people if they had seen him. He felt embarrassed, but also worried about what could have happened to Paul. It made Marcus think about his work with this pupil and consider whether or not to give it up. He finally decided against this, but decided that he had to be more realistic about his relationship with Paul, approaching it as something that was prone to change.

The connections and disconnections with Paul that Marcus experienced can be explained as part of the caring relationship that explicates Marcus' emotional involvement. Aultman et al. (2009) suggest that these movements can be considered as balancing the care and control that serve to maintain a continual negotiation of the reciprocal relationship and connections established between the teacher and the pupil. Through these, Marcus can develop a sense of control over his emotional labour and the personal investment made in his relationship with Paul, with the possibility of re-negotiating and balancing the boundaries of his involvement. The existence of these boundaries is considered necessary because "not having boundaries may lead to burnout and neglect of other important areas of a teacher's life" (Aultman et al., 2009, p. 642). In other words, the lack of boundaries can have an impact on educators' lives outside school.

Teaching experience with pupils is continually dependent on changes that characterise the work that is carried out by educators in different forms. For example, one of the mentors describes this work as "experiential":

The best part of being here is that it is very, very, experiential. The experience is huge (Focus group 4). 
In addition, other educators think that teaching in this PRU is more than just an educational experience:

I think you need to take something new every day. This school means for me a personal growing up and an educational experience (Focus group 4).

Experienced educators have learnt to see their work as having a pendulum-like motion in which the emotional distance from the pupils changes all the time and can sometimes be made less if the gap becomes too wide. They have learnt ways of dealing with these circumstances, for example through the discourse that situates the behaviour of the pupil out of him/herself. This can be seen in the words of one of the teachers when talking about a pupil:

I didn't like his behaviour, but (name of pupil), the boy, I like ... even when he did all the things that he did, I still like him, it is the way he reacts that I don't like. To me this is the way to be sweet to these kids. I like them all for different reasons, but it's their behaviour, you try to separate the child from the behaviour (Focus group 13).

This division gives the educator the opportunity to re-think his/her emotional attachment to the pupil and can be presented as a strategy to keep re-negotiating their relationship. Nevertheless, it can be also problematic: through this emotional separation teachers divide the pupil into two differentiated selves instead of a complex of multiple selves that interact in different contexts. From a poststructuralist perspective this idea of a multiple, reflexive and dynamic self is understood as a liberating concept. This view involves a continuous process of negotiating the discursive practices that enable the construction, reconstruction and representation of subjects in multiple ways. The problem here is that in recognising that pupils have "special talents or capacities", teachers are creating a local form of recognition within the school space that does not transcend the school limits and may actually constrain pupils' subjectivity in other social contexts because the same recognition does not exist outside of school.

Moreover, another form of constructing a positive image of the pupil is representing part of his or herself in a narrative in which the negative aspects are scientifically or pseudo-scientifically approached through biological argumentations, as one educator states:

Some of the kids have this level of excitement ... something in their brain, like something transferred in the pregnancy so they are more aware of danger and triggers so every time something happens it activates them (Focus group 13).

Through this approach the educator sets the limits of his or her involvement by considering some aspects of the pupil's behaviour to be out of the socio-emotional sphere and, therefore, explained under scientific disciplines (a medical, psychiatric, psychological condition, etc.). The educator thus pathologises aspects of the pupil's behaviour. In this form of representing the pupil, the educator finds a way of explaining that there is limit to the work he/she can do, but at the same time the pupil is also represented through a pathologising medical discourse.

\section{Learning to connect teaching experiences with personal experiences}

Experienced teachers from this PRU consider their first experiences with the pupils as difficult ones. An educator who has worked in the unit for more than eight years still remembers his first day as being an emotionally harmful experience that remains a benchmark: 
Things do not hurt so much as the first time (Focus group 10).

The educator is not saying that the negative experiences lived at the beginning have disappeared, rather he suggests that educators at this unit manage to cope with such negative feelings and are able to perceive them differently. Below is a more detailed account of how a new teacher's first day went:

Yesterday I said to myself I didn't think I'd be scared of much and there are not many situations that you can put me where I am reactive ... I could react internally, but I am not usually that nervous outwardly, and yet today ... One of the little boys in the room he just, I could feel actually, I even say to myself I will struggle straight away, and I knew that he wasn't happy with the situation and halfway through, he started cutting. He was doing some really good work actually, and then he started cutting it in a bad way and you could tell he was going to completely erupt, and (name of pupil) was waiting for him to burst and the next thing he did, he just went up in the air and came into the hall but he was freaking out so that you couldn't, rely? It was a tense situation because he was like throwing chairs and it is the worst one I've ever seen, because I've only been here a few days. I feel like panic. It is like all these feelings that you can't show, that you are worried about ... so I have to think: I am scared of this? (Focus group 13).

The experienced educators have developed strategies to cope with the interactions that are considered emotionally negative whereas the new teacher exposes a mix of horror, confusion and uncertainty. The educators who had worked at the unit longer agreed that their first contact with the pupils was similar to the situation which the newcomer experienced. Through experience, educators learn to manage problematic situations with the pupils and to deal with the emotional damage at the same time. On the other hand, some of the educators mentioned cases of staff members who were not able to cope with the work in the unit, and had to give up during their first weeks. Educators are conscious that it is hard work, especially when taking the emotional aspect into consideration. However, emotional learning can be approached as a necessary experience that helps educators to develop their skills and reflect on their emotionality.

Educators had to accept the dynamic of change based on the continuous movement of emotional rapprochement and alienation that represent the performance of emotional geographies. It is for this reason that one of the teachers stated that they had to be "open minded" to develop this kind of work:

You have to be open minded to do this job, you know, you can't be rigid about it, you can't think this is the way it's going to be, you've got to be open minded, you've got to be prepared (Focus group 10).

To be open minded can be understood as a way of recognising a performative emotional identity that invites educators to explore different forms of emotionality. Moreover, it means that the emotional geographies are not standardised although they are sometimes experienced in a similar manner. For example, educators prefer a lesser emotional distance from pupils. However, the way that this interaction is experienced by different educators cannot be exactly the same because emotional experiences involve personal reflection, feeling, cognition and interpretation and these differ from one person to the next (Denzin, 2007). In addition, we have the life experience, background or life story of each person that constitutes themselves in a discursive world (Edwards, 1999) or as part of a narrative (Beatty, 2014), assuming that emotional discourses or narratives give a sense to the way that educators feel about particular situations.

Mentors and teachers construct their own explanations to interpret their emotional relationships with the pupils. For instance, it is interesting to see how they construct this relationship according to 
their own background because they recognise it as similar to the pupil milieu. In other words, they recognise themselves in the pupils:

My background is pretty much like most of the kids, hated school. I was kicked out of different schools in this city at primary age (Focus Group 4).

For another mentor, words were not needed, and he simply pointed to the picture the pupils made when they were disporting themselves to explain how his own background had been. Something like this highlights the differences in the ways that various educators approach the emotional relationship. Some mentors might construct their emotional relationship with pupils through an examination of their own life stories and thus establish a connection. Others find that their background does not help them to connect emotionally with the pupils; nevertheless, they develop other ways of connecting with them, benefiting their own emotional labour at the same time. All the teachers had previous experience teaching in mainstream schools and they seemed to find their opposition to mainstream practices a way to assemble their own emotional discourse based on their ideas of justice, inclusion and attachment to pupils. This is in line with Farouk (2014) who suggests that teachers who work in a PRU are motivated by a moral purpose and a commitment to pupils. To illustrate this idea, when one of the teachers was asked about his background he referred to his socialist ideology as an influence on his life and a reason to disagree with the current educational policy and mainstream practices that ignore the importance of the pupil:

I support the inclusion agenda, but some schools are places where you construct an elitist society and I think that's wrong, I think we should be including everybody. Mainstream schools are factories of education; they are not places where the centre is the children (Focus group 7).

Teachers and mentors are both concerned about establishing different emotional relations with pupils. At the same time, this involvement can only be appreciated if we also consider that it is through the work with the pupils that educators' emotional labour can be manifested and recognised as something positive.

The educators in this unit develop different practices that focus on the socio-emotional development of pupils while also serving to facilitate their emotional approach to them. These practices consist of bringing into play some attitudes and exercises that promote the creation of an encouraging emotional atmosphere in which pupils can consider themselves safe. For example, some of these attitudes consist of the continuous reinforcement of the positive behaviours of the pupils with constructive commentaries, even when they are not strictly academic matters. In addition, pupils are always called by their names; teachers and mentors avoid shouting at them too, so as not to provoke a disturbance in the relaxed atmosphere. Educators' emotionality is in constant negotiation and, thus, emotional learning is embedded in their daily practices as a constitutive element of their identity.

\section{Learning to construct "different" narratives}

It would be fair to say that teachers enjoy working with pupils even when they are involved in extreme circumstances, because they find having relationships with pupils rewarding (Golby, 1996; Hargreaves, 1994, 1998, 2000; Lortie, 1975; Nias, 1989; Sutton \& Wheatley, 2003). But do educators prefer the emotional distance between themselves and pupils to be less rather than more? Do educators experience more personal satisfaction through the caring attitude they employ in their work? 
Without doubt, the teacher-pupil relationship can be problematic. As Piper and Stronach (2008) argue, a culture of distrust and fear, which erodes educators' emotional involvement, has been created around it.

Interactions with pupils are described by educators as positive emotional experiences. For instance, when pupils who have left the unit return to visit, this is perceived by educators as an affirmative stimulus that compensates for some of the challenging moments they experienced when working with the pupils. Educators use this as motivation to continue and do not give up developing skills to use in their difficult work, finding a personal reward in the teacher-pupil reunion (Lortie, 1975). An illustration of this can be found in the words of some of the educators participating in this research:

We have a lot of kids who come back two or three years later, grown up, doing ok, to say: Hi! I do not forget this because ...(Focus group 5).

It is wonderful to see them again, I think. When they come back and make you feel that should carry on doing that, it makes all ...(Focus group 5).

These affirmations are the educators' way of expressing their gratification at the fact that they are still recognised by the pupils as having played a part in their lives.

In other conversations, one of the mentors related a story about a former pupil who returned to visit the unit after being in prison. The mentor found it remarkable that somebody who was not used to deferring to any authority was being respectful to him. The mentor explained that during the pupil's visit, he did not allow him to swear or smoke within the building and the pupil accepted this without causing any trouble and without showing any resentment towards the mentor or challenging his authority. The mentor was pleased about this; although it was sad for him to think about one of his former pupils having been in prison, he felt that his work with the pupil had not been completely wasted because the pupil was able to be respectful towards him.

Based on his own experience, one of the teachers at the PRU asserted that educators working in mainstream education would be seriously disappointed with a narrative telling like the presented above. This teacher explained that a narrative telling the story of a pupil who was in prison could be understood as a total failure on the part of a teacher in a mainstream school. However, it was heartwarming to note how the educators in the PRU managed to find something positive in the pupil's story, putting aside the negative aspects. While emotional exhaustion is associated with the teacherpupil relationship (Chang, 2009; Evers et al., 2004; Isenbarger \& Zembylas, 2006) and it is at risk of breaking down (Flores \& Day, 2006), it also provides opportunities for educators to engage in new ways of understanding themselves, their personal and professional engagement and the moral purpose of their work. This possibility of negotiating new forms of engagement is considered to be one of the main reasons that motivates teachers to move from mainstream schools to PRUs (Farouk, 2014).

Educators are conscious that their possibilities of intervening in the life of their pupils are based on establishing a close emotional relationship that permits teachers and mentors to operate in a different way from that in which they did at their previous schools. They are continually showing their dissatisfaction with the way that education is organised through subjects, impersonal rules, paperwork and evaluations that disconnect the pupil from his/her background and therefore ignore other social and emotional aspects of education that the educators in this unit recognise as essential. With reference to this, one of the educators said:

I stood nine years in mainstream schools, I did a lot of work with regard to special needs in mainstream schools, but I don't think the idea of mainstream schools is the way. Mainstream schools are set up, you can't go as far as you need to go with these children because they have to be in the class and just learn science, maths and English (Focus group 4). 
These words reclaim a way of understanding educational practices that allows the educator working with pupils who have special needs to focus on other aspects of child development. It is a claim for a more holistic education that considers the socio-emotional aspects involved in the educational process. The way in which special education and the education of pupils who do not fit into mainstream education is approached is perceived by the educators of this unit as something that continually disconnects teachers from pupils and, as a consequence, makes the educators participating in this study feel uncomfortable about their work. Furthermore, it also makes the educator consider his/her options and what sort of teaching he/she would prefer. This idea is discussed in the following extract:

With the new political [or policy] interest in education, I could see how they put lot of money into the schools, but along with the money comes a lot of pressure, and it made me feel confused and made me think about what my idea about education is (Focus group 7).

Staff working in this PRU do not see themselves as being free from pressure at work. Following Foucault's ideas (1995), pressure can be connected to the idea of power as being something unavoidable because it is an essential instrument for the constitution of subjectivity. In the previous extract could be observed how perceived excessive pressure has a negative impact, making educators question their beliefs about education, whereas when this pressure is exerted in a different way that is not perceived as negative, it is felt by educators as something constructive:

It was a small project; pressure is the same as in the rest of the school, but put in a different way, and it is good because it lets you have more space (Focus group 4).

The problem, therefore, is not the presence of power, but the way that it dominates different aspects of the educators' teaching practices and the way in which they construct their identity as educators. Teachers, and in particular mentors, seem to find in their educational practices developed in this unit a way to achieve emotional understanding that will be of benefit not only to interact with the pupils but also to give meaning to their emotional experience.

\section{Conclusion}

This study has explored how the emotional learning of educators takes place in a PRU. The idea of emotional geography introduced by Hargreaves is brought into play as a conceptual tool used to understand how emotional learning is connected with the educator-pupil relationship. Their emotional interaction is represented as a central matter of the learning process and, thus, understood as developed at a lesser emotional distance. However, the discussion presented in this paper represent the emotional learning of the educators working in this PRU as something that takes place at varying distances. Educators learn to approach their emotional involvement as something dynamic and performative. Drawing on emotional experiences they learn to deal with different emotional distances.

This research has discussed different strategies embedded in emotional learning that allow the educators to manage their emotional involvement. The emotional learning explored in this study can be summarised in different practices that educators develop to represent their emotional labour and their emotional relationship with pupils.

The paper illustrates how educators, by learning to transform negative narratives into positive ones, are able to explore different ways of representing their relationship with pupils, allowing them to deal with their emotional work experiences more confidently. Moreover, it also considers how in an alternative provision emerges a discourse that challenges the representation of the dominant mainstream 
education teacher-pupil relationship. Educators learn new ways of organising their emotional labour, articulating their relationship with pupils at a lesser emotional distance, recognising that their job demands both superficial and deeper involvement but not suppression of emotions (Näring, Vlerick \& Van de Ven, 2012). Nevertheless, this relationship cannot be based only on a lesser distance because, as was previously explained, this has been recognised as being harmful to educators (Hochschild, 2003) and pupils alike (Aultman et al., 2009). For this reason, educators learn to represent their relationship with pupils as a pendulum-like motion in which they develop strategies to organise their engagement and disengagement with the pupils, so being able to do their work at different emotional distances. Through the data previously discussed, it can be understood how educators learn to construct different representations of pupils (perhaps depicting them in a scientific discourse), or how educators connect pupils' life stories with their own experiences, in order to manage the emotional distance between them.

This study also shows how the educators in this PRU consider emotional learning necessary to facilitate their teaching, thus enabling them to meet the emotional demands placed upon them. Educators who do not reflect on this learning are ignoring the importance of the emotional aspects of teaching and run the risk of failing in their engagement with pupils. The problem is that this can have a damaging impact on their professional subjectivity, their teaching practices and even on their private lives.. Educators in this PRU (in particular mentors) construct their identity around the belief of teaching as an emotional practice that in a context like this cannot be understood without its emotional involvement. However, bearing in mind that the emotional demands can lead to forms of emotional exploitation-appropriation (Brook, 2009; Colley, 2006), emotional exhaustion (Tsouloupas et al., 2010) or dehumanisation (Shapiro, 2010; Zembylas, 2007a), this paper has argued that educators have developed ways of managing this emotional stress. From their experiences with pupils, teachers and mentors learn different strategies that facilitate their emotional involvement at work and which at the same time help them to avoid some of the problems associated with the emotional labour that they perform.

Finally, this emphasis on the importance of emotional learning might be understood as a way of supporting the social character of "feeling" in the workplace rather than a process individually and privately managed

\section{Notes}

1. Hargreaves' concept of emotional geography should not be confused with emotional geography as a discipline dependent on geography, which attempts to understand the emotions of people with regard to geographical phenomena such as the creation and representation of emotional meanings of places, demographic movements or physical spaces (see Davidson et al., 2005).

2. The term educator will be used in this paper to refer to both mentors and teachers. It is also used when a differentiation between mentor and teacher is considered unnecessary.

3. The names of individuals have been changed in order to maintain their anonymity.

\section{References}

Ahmed, S. (2015). The cultural politics of emotion (2 $2^{\text {nd }}$ ed.). New York, NY: Routledge.

Aultman, L.P., Williams-johnson, M.R., \& Schutz, P.A. (2009). Boundary dilemmas in teacher-student relationships: struggling with "the line". Teaching and teacher education, 25, 639-646.

Beatty, A. (2014). Anthropology and emotion. Journal of the Royal Anthropological Institute, 20, 545563.

Boler, M. (1999). Feeling power: emotions and education. London, England: Routledge. 
Brook, P. (2009). The alienated heart: Hochschild's emotional labour thesis and the anticapitalist politics of alienation. Capital and Class, 33(7), 7- 31.

Chang, M.L. (2009). An Appraisal Perspective of Teacher Burnout: Examining the Emotional Work of Teachers. Educational Psychology Review, 21, 193-218.

Colley, H. (2006). Learning to labour with feeling: class, gender and emotion in childcare education and training. Contemporary Issues in Early Childhood, 7(1), 15-29.

Davidson, J., Bondi, L. \& Smith, M. (2005). Emotional Geographies. Hampshire, England : Ashgate Publish Limited.

Deleuze, G. \& Guattari, F. (2004). A thousand plateaus. London, England: Continuum.

Denzin, K. N. (2007). On understanding emotion. New Jersey, NJ: Transaction Publisher.

Flores, M. \& Day, C. (2006). Context which shape and reshape new teachers' identities: A multiperspective study. Teaching and teacher education 22, 219-232.

Egerton, (1995). Emotions and discursive norms. In Harré, R. and Stearns, P. (Eds.), Discursive Psychology in practice (pp.183-193). London, England: Sage.

Evans, D. (2001). Emotion: a very short introduction. Oxford, England: Oxford University Press.

Evers, W.J.G., Tomica, W. \& Brouwers, A. (2004). Burnout Among Teachers: Students' and teachers' Perceptions Compared. School Psychology International, 25 (2), 131-148.

Ewards, D. (1999). Emotion discourse. Culture and Psychology, 5 (3), 271-280.

Farouk, S. (2014). From mainstream school to pupil referral unit: a change in teachers' selfunderstanding. Teachers and teaching: theory and practice, 20 (1), 19-31.

Fineman, S. (2000). Emotion in organisation. London, England: Sage.

Fineman, S. (2003). Understanding emotion at work. London, England: Sage.

Fisher, C. D., \& Ashkanasy, N. M. (2000). The emerging role of emotions in work life: An introduction. Journal of. Organizational Behavior, 21, 123-129.

Foley, R. M., \& Pang, L-Z. (2006). Alternative education programs: Program and student characteristics. The High School Journal, 89, 10-21.

Foucualt, M. (1995). Discipline and Punish. New York, NY: Knopf Dubleday.

Freid, R. (1996). The passionate teacher. Boston, MA: Bacon Press.

Golby, M. (1996). Teachers' emotions: An illustrated discussion, Cambridge Journal of Education, 26, $423-435$.

Goleman, D. (1999). Working with emotional intelligence. London, England: Bloomsbury.

Gutherson, P., Davies, H. and Daszkiewicz, T. (2011). Achieving successful outcomes through Alternative Education Provision: an international literature review. Reading: CfBT Education Trust.

Hargreaves, A. (1994). Changing teachers, changing times: Teachers' work and culture in the postmodern age. London, England: Cassell.

Hargreaves, A. (1998). The emotional practice of teaching. Teacher and Teaching education, 14 (8), 835-859.

Hargreaves, A. (2000). Mixed emotions, teachers' perceptions of their interactions with students. Teaching and Teacher education, 16, 811-826.

Hargreaves, A. (2001a). The emotional geographies of teaching. Teachers College Record, 103, 10561080 .

Hargreaves, A. (2001b). The emotional geographies of teachers' relations with colleagues. International Journal of International Research, 35, 503-527.

Hargreaves, A. (2004). Inclusive and exclusive educational change: emotional responses of teachers and implications for leaderships. School leadership and management, 24 (3), 287- 309.

Harper, A., Heron, M., Houghton E., O'Donnell S. and Sargent C. (2011). International Evidence on Alternative Provision (INCA Thematic Probe). Slough: NFER 
Harré, R. (Ed.) (1986). The social construction of emotions. London, England: Basil Blackwell.

Harré, R. \& Parrot, W. G. (Eds.). (1996). The emotions: Social, Cultural and Biological Dimensions. London, England: Sage.

Hochschild, A. R. (2003). The managed heart [20 years edition]. London, England:University of California Press.

Isanbarger, L. \& Zembylas, M. (2006). The emotional labour of caring in teaching. Teacher and Teaching education, 22, 122-134.

Kerr, M.M. and Brown, E.L. (2016) Preventing School Failure for Teachers, Revisited: Special Educators Explore Their Emotional Labor. Preventing School Failure: Alternative Education for Children and Youth, 60 (2), 143-151.

Kitzinger, J., \& Farquhar, C. (1999). The analytic potential of 'sensitive moments' in focus group discussions. In R.S. Barbour \& J. Kitzinger (eds.), Developing focus group research: Politics, theory and practice (pp. 156-173). London: Sage.

Liamputtong, P. (2007). Researching the vulnerable: A guide to sensitive research methods. London: Sage.

Liamputtong, P. (2016). Focus group methodology: Principles and practice. London: SAGE

Lortie, D. C. (1975). Schoolteacher: a sociological study. Chicago, IL: University of Chicago Press.

Madriz, (2000). Focus group in feminist research. In N. K Denzin,. \& Y. Lincoln, (Eds.), Handbook of Qualitative Research (pp.835-850). London, England: Sage.

Näring, G.; Vlerick, P. and Van de Ven, B. (2012). Emotion work and emotional exhaustion in teachers: the job and individual perspective. Educational Studies, 38 (1), 63-72

Nias, J. (1989). Primary teachers talking: a study of teaching at work. London, England: Routledge.

Nias, J. (1996). Thinking about feeling: The emotions in teaching. Cambridge Journal of Education, 26, 293-306.

Oatley, K. (2004). Emotions: a brief history. Oxford, England: Blackwell.

Pekrun, R. \& Linnenbrink-Garcia, L. (Eds.). (2014). International handbook of emotions in education. New York, NY: Routledge.

Pipper, H. \& Stronach, I. (2008). Don't touch! The educational story of panic. London, England: Routledge.

Pirrie, A., Macleod, G., Cullen, M.A. \& McCluskey, G. (2011). What happens to pupils permanently excluded from special schools and pupils referral units in England? British Education Research Journal, 37 (3), 519-538.

Pomeroy, E. (2000). Experiencing exclusion. Stoke on Trent, England: Trentham.

Price, H. (2001). Emotional labour in the classroom: a psychoanalytic perspective. Journal of Social Work Practice, 2, 161-180.

Reddy (2001). The navigation of emotions: a framework for the history of emotions. Cambridge, England: Cambridge University Press.

Schutz, P. A. \& Pekrun, A. (2007). Emotion in Education. Burlington, England: Elsevier.

Shapiro, S. (2010). Revising the teachers' lounge: reflections on emotional experience and teacher identity. Teaching and teacher education, 26, 616-621.

Schneck, S. (1987). 'Michel Foucault on Power/Discourse. Theory and Practice. Human Studies, 10,1533.

Shutton, R. \& Wheatley, K. (2003). Teachers' emotion and teaching: a review of the literature and directions for future research. Educational psychology review, 15(40), 327-358.

Steinberg, R. J. \& Figart,D. M. (1999). Emotional Labour since the managed heart. Annals of the American Academy Academy of Political and Social Sciences, 56, 8-26.

Tsouloupas, C.N., Carson, R., Matthews, R., Grawitch, M.J. \& L.K. Barber (2010). Exploring the association between teachers' perceived student misbehaviour and emotional exhaustion: the 
importance of teacher efficacy beliefs and emotion regulation. Educational Psychology: An International Journal of Experimental Educational Psychology, 30(2),173-189.

Van Veen, K. \& Lasky, S. (2005). Emotions as a lens to explore teacher identity and change: different theoretical approaches. Teacher and teacher education, 21, 895-898.

Watkins, M. (2016). Gauging the affective: becoming attuned to its impact in education. In M. Zembylas, \& P. Schutz (eds.) Methodological Advances in Research on Emotion and Education. (pp.71-83). Switzerland: Springer.

Zembylas, M. \& Schutz, P. (2009). Research on teachers' emotions in education: findings, practical implications and future agenda. In Schutz, P. \& Zembylas, M. (Eds.) Advances in teacher emotion research (pp.367-377). New York, NY: Springer.

Zembylas, M. (2002). Constructing Genealogies of Teachers' Emotions in Science Teaching. Journal of Research in Science Teaching, 39(1), 79-103.

Zembylas, M. (2003). Emotions and teacher identity: a poststructural perspective. Teachers and teaching: theory and practice, 9, 213-238.

Zembylas, M. (2005a). Teaching with emotion. A postmodern enactment. Greenwich, England: Information Age.

Zembylas, M. (2005b). Discursive practice, genealogies and emotional rules: a poststructuralist view of emotion and identity in teaching. Teaching and teacher education, 21, 935-948.

Zembylas, M. (2007a). Emotional capital and education: theoretical insights from Bordieu. British Journal of Educational Studies, 55 (4), 443-463.

Zembylas, M. (2007b). Theory and methodology in researching emotions in education. International Journal of Research \& Method in Education, 30 (1), 57-72.

Zembylas, M. (2014). The place of emotion in teacher reflection: Elias, Foucault and 'critical emotional reflexivity'. Power and Education, 6 (2), 210-222

Zembylas, M. (2016) Teacher resistance to engage with 'alternative' perspectives of difficult histories: the limits and prospects of affective disruption. Discourse.

Zembylas, M. (2017) Love as ethico-political practice: Inventing reparative pedagogies of aimance in "disjointed" times. Journal of curriculum and pedagogy 14 (1). 